\title{
EFFECT OF SOIL TYPES AND MIXTURES ON NODULATION OF SOME BEANS AND GROUNDNUT VARIETIES
}

\author{
Uaboi-Egbenni PO* ${ }^{1}$, Okolie $\mathrm{PN}^{2}$, Okafor $\mathrm{CN}^{3}$, \\ Akinyemi $\mathrm{O}^{4}$, Bisi-Johnson $\mathrm{MA}^{5}$ and OD Teniola ${ }^{6}$
}

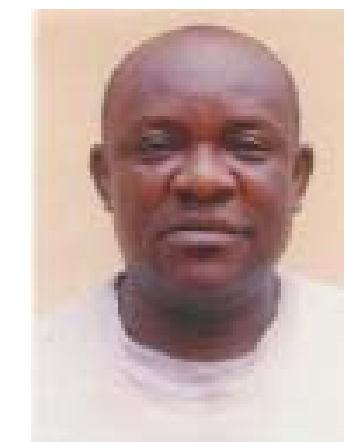

\section{Peter Uaboi-Egbenni}

*Corresponding author email: peteregbenni_3@yahoo.com

${ }^{1}$ University of Venda, Department of Microbiology, P.B.5050, Thohoyandou, Limpopo Province, South Africa. Member: Nigerian Society For Microbiology [NSM]; Association of Industrial Microbiologists of Nigeria [AIMN]; Nigerian Society For Botany [NSB]

${ }^{2}$ Yaba College of Technology, Department of Food Technology, P.M.B. 2011, Yaba Lagos, Nigeria. Member: Nigerian Society For Food Science and Technology [NSFST].

${ }^{3}$ Yaba College of Technology, Department of Biological Science, Microbiology Unit, P.M.B. 2011, Yaba Lagos, Nigeria.

${ }^{4}$ University of Venda, Department of Statistics, P. Bag. 5050, Thohoyandou, South Africa. Member: Nigerian Statistical Association [NSA].

${ }^{5}$ Department of Biotechnology, Federal Institute of Industrial Research, Oshodi, Lagos, Nigeria (FIIRO). Nigerian Society for Microbiology (NSM); Association of Industrial Microbiologists of Nigerian (A.I.M.N).

${ }^{6}$ Department of Medical Microbiology, Walter Sisulu University, Mthatha, Eastern Cape, South Africa. Nigerian Society for Microbiology [NSM]. 


\section{ABSTRACT}

Groundnuts and beans have long been recognized as good sources of proteins and essential amino acids. Groundnut on its part is a good source of vegetable oil. The types of soil, rhizobia and nutrient components of the soil have long been known to affect the productivity and growth of nodule-forming legumes. This information was the basis of a field study carried out at the Yaba College of Technology botanical garden to determine nodule formation by soil types and their mixtures in five (5) beans and two (2) ground cultivars. Nodules were formed by all the beans and groundnut varieties in loamy soil. Beans variety 3 (brown/white beans) formed 19 nodules, while groundnut, Arachis hypogea ALR2 26 nodules. All beans varieties nodulated in humus soil, but less number of nodules were formed compared with loamy soil. Of the two groundnut varieties investigated, only Arachis hypogea ALR2 nodulated in humus soil. Beans 5 alone (brown/molted beans) nodulated in sandy soil. Groundnut ALR2 formed nodules in all the soil mixtures (except humus/loamy) than any of the beans varieties with mean nodules as high as twenty-eight (28) in clay/loamy soil. Analysis of the results using SPSS Version 17 showed that number of nodules and diameter of each plant stem are not significant at 5\% confidence level $(\mathrm{P}<0.005)$, while size of nodule formed is significant. In addition, there is significant positive association for nodule size and nodules numbers for clay soil at 5\% confidence level $(\mathrm{P}<005)$, whereas there is significant negative association for nodules size and numbers for clay and humus mixtures at $5 \%$ confidence level $(\mathrm{P}<0.005)$. Using independent t-test for difference in means between nodules number and size, it was found that only sand/clay mixture and clay/humus are significant at 5\% $(\mathrm{P}<.005)$ confidence level, while other soil types and their mixtures were not significant at the same level of confidence. This means there is no significant difference between the means of the number of nodules and nodule size. From the statistical analysis, clay and sandy soils were poor in encouraging nodule formation as they have the highest mean differences.

Key words: beans, groundnut, loamy, nodules, cultivars 


\section{INTRODUCTION}

Biological fixation of atmospheric nitrogen is estimated to account for $\sim 90 \%$ of the 100 to $140 \mathrm{Tg}$ of nitrogen $\left(1 \mathrm{Tg}=10^{12} \mathrm{~g}\left[10^{6}\right.\right.$ metric tons]) fixed annually in terrestrial environments. The remaining $10 \%$ was fixed abiotically, primarily by lightning $[1,2$, 3]. Human activity, especially the generation of ammonium compounds for agricultural fertilizers, fossil fuel consumption, and increased planting of legumes, contributes an estimated $140 \mathrm{Tg}$ of additional fixed nitrogen each year $[4,5]$. Biological nitrogen fixation is catalyzed by prokaryotes only, so far as it is known. The enzyme complex responsible for nitrogen reduction is called nitrogenase. It is irreversibly inactivated by oxygen. Hence the process requires conditions that are anoxic or nearly anoxic [4].

The process of symbiotic nitrogen fixation is, for the most part, a property exhibited exclusively by some group of bacteria, including the genera Rhizobium, Mesorhizobium, Sinorhizobium, Bradyrhizobium, and Azorhizobium. All but the last of these is from the $\alpha$-proteobacterial Rhizobaceae family and induce nodules on plants from the Leguminosae family. Rhizobia carry most of the genes specifically required for nodulation either on large (500- kbp to $1.5-\mathrm{Mbp})$ plasmids or on symbiosis islands $[6,7]$. More strikingly, it has recently been discovered that bacteria that do not belong to the Rhizobiaceae can induce nodules on legumes [5]. For a strain of Methylobacterium, an $\alpha$-proteobacterium, can nodulate Crotalaria, and $\beta$ proteobacteria related to Burkholderia can nodulate Machaerium lunatum and Aspalathus carnosa [5]. Apparently, these species have acquired, by horizontal gene transfer, plasmids or islands that contain many of the same genes used by typical Rhizobiaceae to induce nodule formation and catalyze nitrogen fixation [5].

Plants grown on soils with a large population of Rhizobium and allied microbes form nodules at the root of the plant, especially leguminous plants such as beans and groundnuts during root infection [8]. In response to attached bacteria, roots hairs deform and curl, setting up a pocket that provides a site for infection-thread initiation [9]. Some studies done elsewhere observed nodulation in the absence of Rhizobium in white clover plant (Trifolium repens)[10]. Presence of bacterial microsymbionts is indispensable for formation of functional nitrogen-fixing root nodules, but previous work reported the capacity of certain varieties of alfalfa and clover to develop empty nodules in the absence of rhizobia [11].

The leguminosae is one of the largest plant families and includes agronomically important species such as soybean, beans, pea, peanuts, and forage legumes. One of the agricultural and ecological advantages of legumes is their ability to establish symbiosis with nitrogen-fixing bacteria, known collectively as rhizobia [5, 11]. High levels of nitrate will, for example, suppress nodule formation and shift nitrogen metabolism towards growth on nitrate [12]. 
Legume plants associate with bacteria belonging to the genera Rhizobium, Mesorhizobium, Sinorhizobium, Bradyrizobium, Azorhizobium, collectively referred to as rhizobia to form symbiotic nodules on plant roots $[13,14]$. The stages involved in root infection by rhizobial organisms with eventual formation of root nodules have been described by several researchers $[5,11,14]$. In two separate studies it was observed that arabidiopsis develops unusually short root hairs as they lack the enzymes capable of catalyzing the formation of reactive oxygen species (ROS), which is needed for the normal elongation of root hairs in Arabidopsis [5, 15].

Legume-nodulating bacteria associated with Phaseolus vulgaris (common beans) were characterised in Morocco by Priefer et al. [16] and in Tunisia by Mhamdi et al. [17], where they were assigned to R. gallicum bv. gallicum, R. leguminosarum $b v$. phaseoli and bv. viciae, R. etli bv. Phaseoli, R. giardinii bv. Giardinii, S. medicae and $S$. fredii species. Aouani et al. [18] showed differential common bean nodulation efficiency depending on the bacterial strain. Legume nodulating bacteria from chickpea (Cicer arietinum L.) have been described as Mesorhizobium ciceri, M. mediterranean and Mesorhizobium sp [19, 20].

Soybeans (Glycine max L. Merr.), groundnut (Arachis hypogea L.) and Common beans (Phaseola vulgaris L.) are broadly grown in several countries all over the world including Brazil as protein sources and, in the case of the first and the second crops, also for oil production. These legumes establish symbiotic associations with soil bacteria which form spherical determinate nodules, where the process of $\mathrm{N}_{2}$ fixation takes place [21]. They also noted that nodulation appear more at the crown region of the root instead of the whole root system.

The aim of this study was to determine the effect of soil types and their mixtures on the nodulation of some leguminous plants (beans and groundnut) and ascertain if there is any significant difference in nodule formation among soil types on legumes based on the number of nodules formed and size of nodules. It is also expected that the effect of soil types and nodules on the diameter of plant stems will be determined. Make appropriate recommendation from the results obtained of the best soil type and their mixtures that will support efficient growth of these plants under study. The statistical correlation between nodule numbers and nodule size will also be determined using SPSS Version 17 analytical tool.

\section{MATERIALS AND METHODS}

\section{Biological materials}

A collection of five beans and two Groundnut varieties were used in this study. They were obtained from Nigeria Stored Product Research Institute (NSPRI), Lagos office, Lagos State in their best condition. They include brown mottled cowpea1, brown mottled cowpea II, black eye beans, sweet cowpea and white/brown cowpea; Arachis hypogea ALRI and Arachis hypogea ALR2. The plant seeds were designated as follows. Sweet beans (Bean 1), Black eye Bean ( Bean 2), Brown/white bean (Bean 
3), Brown mottled Bean1 (Bean 4), Brown mottled Bean 2 ( Bean 5), Arachis hypogea ALR1 (Groundnut 1), Arachis hypogea ALR2 (Groundnut 2).

\section{Soil source}

All soil samples were obtained from Lagos State Ministry of Agriculture and Natural Resources (LSMANR), Department of Agriculture in their prepared state; hence there was no need for sieving. Other materials, pots, hand trowel, calibrated bowl, bucket, were bought from the local market in Mushin area of Lagos State, while metre rule, oven, and electric boiler were available in the Department Biological Science, Yaba College of Technology, Yaba Lagos.

Seeds at their best state of health were selected and surface - sterilized as described previously [22]. Thereafter, they were pre-soaked in sterile water overnight, and were grown in different soil types and their mixtures in sterile nursery bags $\left(25 \mathrm{~cm}^{2}\right.$ in diameter and height $25 \mathrm{~cm}$ ). Only the soils for the control were sterilized in an oven at $180^{\circ} \mathrm{C}$ for $1 \mathrm{hr}$.

The individual soil types, their mixtures and control soils were filled into nursery bags. There were ten soils (including mixed soils) samples in all. In the case of beans varieties each soil had five nursery bags into which three bean seeds were sown randomly to ensure that competition between the growing seedlings for nutrients is drastically reduced. The same process was repeated for all soils used. For each soil type, a control nursery was seeded with three bean seeds in order to ensure adequate representation and reliability of results. In all, two hundred nursery bags were used for the study on beans. The same procedure was repeated for the groundnut studies except that in this case, eight nursery bags were used. For clay/loamy, equal weight of each soil (10kg: $0 \mathrm{~kg}$ ) was taken and mixed properly with a calibrated bowl. Water was added to each nursery bag to wet, while sterile water was used for the control. Wetting was done every other day. Efforts were made to prevent water logging of the nursery bags. Germination and growth of plants was observed for two months within which period nodule formation for each plant was observed for a period of five (5) weeks after germination and the average number of the nodules, nodule sizes and stem diameter were measured. Measurements were done at intervals of four days using a well graduated metre rule. The results obtained were as displayed in the accompanying graphs in the result section.

\section{RESULTS}

The average number of nodules, their sizes and stem diameter $(\mathrm{mm})$ formed on the roots of Beans and Groundnut varieties on soil types and their mixtures were as shown in Fig.s1-10. Commencement of growth was accompanied with counting of the number of nodules after five (5) days of germination and counting was done for 30 days at intervals of 4 days. Measurements of size of nodules as well as the diameter of the plant stems were determined using a metre rule. The values displayed in Fig.s1-10 are pulled mean values for all measurements. Nodule formation was 
observed in all soil types and their mixtures employed in this investigation except for sandy and clay soil where only Beans 5 and 2 nodulated, respectively.

\section{Loamy Soil}

This soil appears to favour nodule formation for all beans and Groundnut varieties. However, nodule abundance was higher in Bean 4, 5, 2 and 3 (5, 5, 6 and 19 nodules respectively) and in Groundnut variety 2 with 25 nodules. In terms of nodule formation in this soil, Beans 2 and Groundnut 2 were most efficient at forming nodules (Fig.1). It is evident that the size of the nodules and diameter of the stem are independent of the number of nodules.

\section{Humus soil}

All plant varieties nodulated on this soil type except Groundnut ALR1. However, beans 3 formed more nodules than all plants under study with an average number of 12 nodules (Fig.2). The diameter of the stem and the size of nodules do not depend on the number of nodules formed.

\section{Sandy soil}

Sandy soil did not support nodule formation. However, it supported the growth of Beans 5, which formed average nodule number of three (3). More importantly, inability to nodulate did not affect growth and diameter of the plant stems. Both groundnut cultivars did not nodulate in this soil type (Fig. 3).

\section{Clay soil}

This soil type did not support nodule formation for most of the beans variety except Beans 2 and Beans 5 with average nodules of 13 and 11 respectively. In addition, the Groundnut varieties (ALR1 and 2) did not nodulate in this soil. The diameter of the stem was also independent of the presence or absence of nodules (Fig.4).

\section{Humus/loamy soil}

All Beans varieties nodulated in this soil mixture with nodule formation more skewed to Beans 2 and 4 with more nodules than the rest Bean varieties. There were no nodules formed for the two Groundnut varieties in this soil mixture (Fig.5). The diameter of the stem and size of the nodules were independent of the number of nodules formed.

\section{Sandy/loamy soil}

This soil mixture apparently favoured nodulation in all variety of beans. In addition, it also favoured nodulation in one of the Groundnut variety, ALR2. However, ALR1 neither nodulated nor grew in this soil mixture. The diameter of the stem and size of nodule were as well independent of the number of nodules (Fig.6). Groundnut ALR2 produced more nodules ( 26 nodules) than all the Bean varieties.

\section{Clay/sandy soil}

Nodules were disproportionately formed in all the plant varieties examined. All Beans' varieties nodulated in this soil mixture. Only Groundnut ALR2, nodulated in

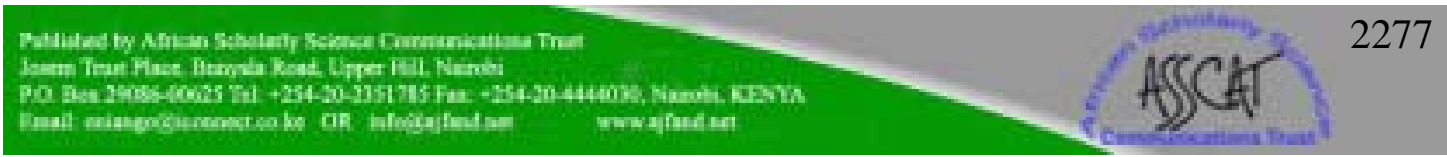


this mixture and developed more nodules (22 nodules) than all the plants studied. Groundnut ALR 1 did not form any nodule in this soil mixture. The diameter of the stem and the size of the nodules were also noted to be independent of the number of nodules formed by individual plant varieties (Fig. 7).

\section{Clay/Loamy}

All bean varieties but one (Beans 2) nodulated efficiently in this soil mixture. Groundnut ALR2 formed largest average number of twenty-eight (28) nodules in this soil mixture. Groundnut ALR1 did not nodulate in this soil mixture. The soil mixture seems to favour abundant formation of nodules in all the plants it supported except Groundnut ALR1 (Fig. 8).

\section{Clay/humus soil}

All beans varieties as well as Groundnut ALR2 nodulated well in this soil mixture. However, Groundnut ALR1 did not initiate nodule formation. Groundnut 2 had more average number of nodules (18) than all the plant varieties (Fig.9).

\section{Sandy/humus soil}

Nodulation occurred in all the beans varieties but the number was less than the values obtained for other soil mixture. Beans 2 and 4 formed more nodules than other bean varieties with maximum mean values of 5. All groundnut varieties did not nodulate in this soil mixture. As usual, the nodule size and stem diameter were independent of the number of nodules formed (Fig.10).

The inference made on the effect of soil types and mixtures on the extent of nodulation of groundnut and beans is that Groundnut variety ALR1 could not nodulate on all soil types and mixtures except on loamy soil where it formed eleven (11) nodules. Groundnut variety ALR 2 grew better than all beans varieties on loamy, sandy/loamy, clay/loamy and clay/humus soils. This observed phenomenon could be explained on account of the degree of aeration and nutrient level offered by these soil types and their mixtures. The beans varieties nodulated on all soil types and their mixtures, but not on sandy soil and on clay soil in which Beans varieties 1, 3 and 4 did not also nodulate. Hence, soil type could play a significant role in legume nodulation and therefore plant productivity. 
No of nodules, nodule size and diameter of stem $(\mathrm{mm})$

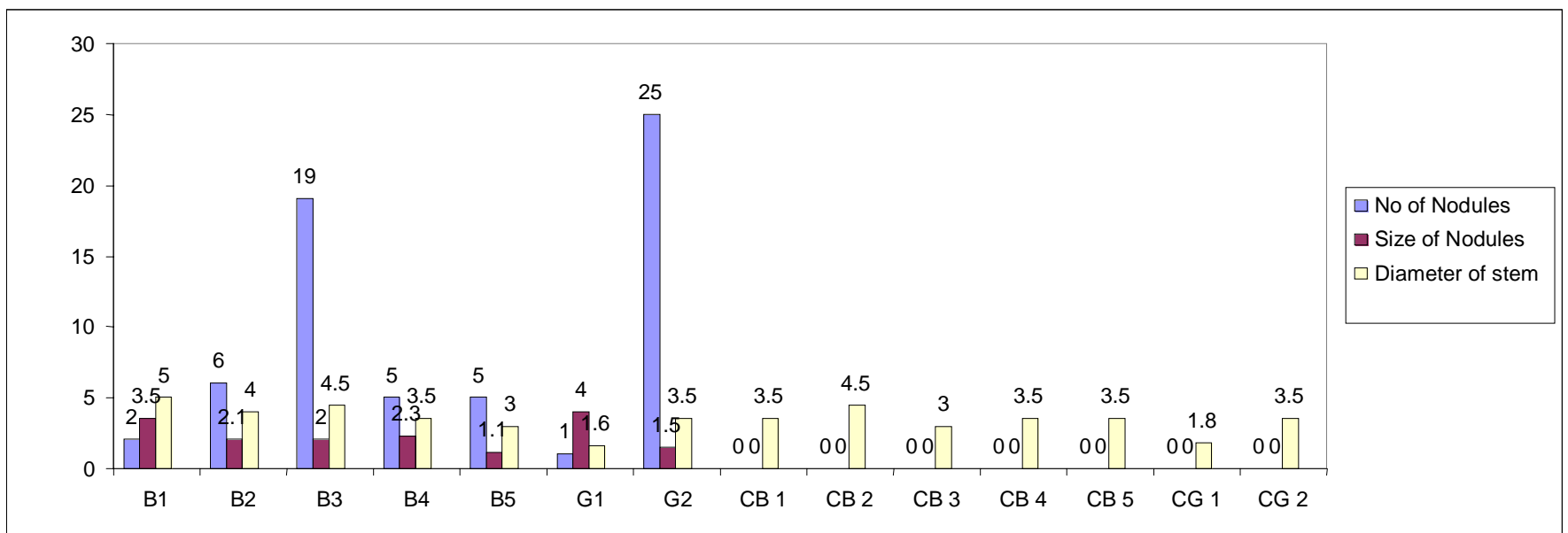

Figure 1: Composite bar chart showing numbers of nodules, nodule size and stem diameter of beans and groundnut varieties grown on loamy soil and their control

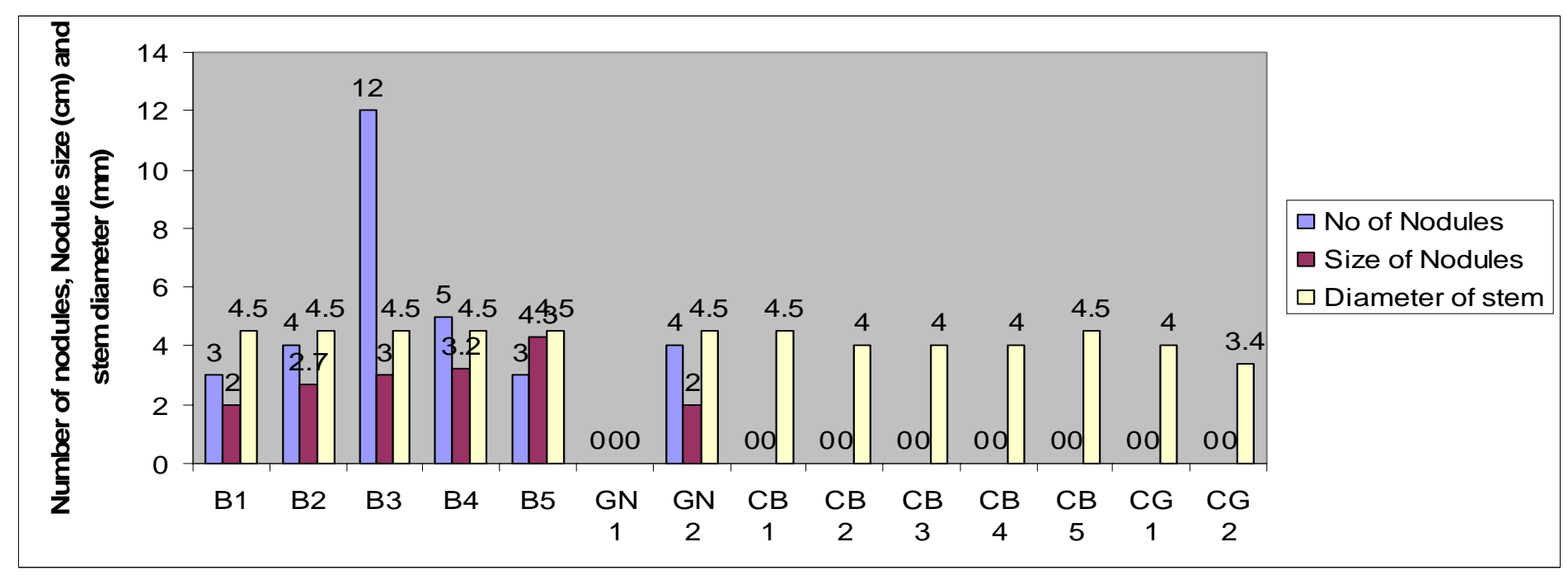

Figure 2: Composite bar chart of number of nodules, nodule size and stem diameter of beans and groundnut varieties grown on humus soil and their control 


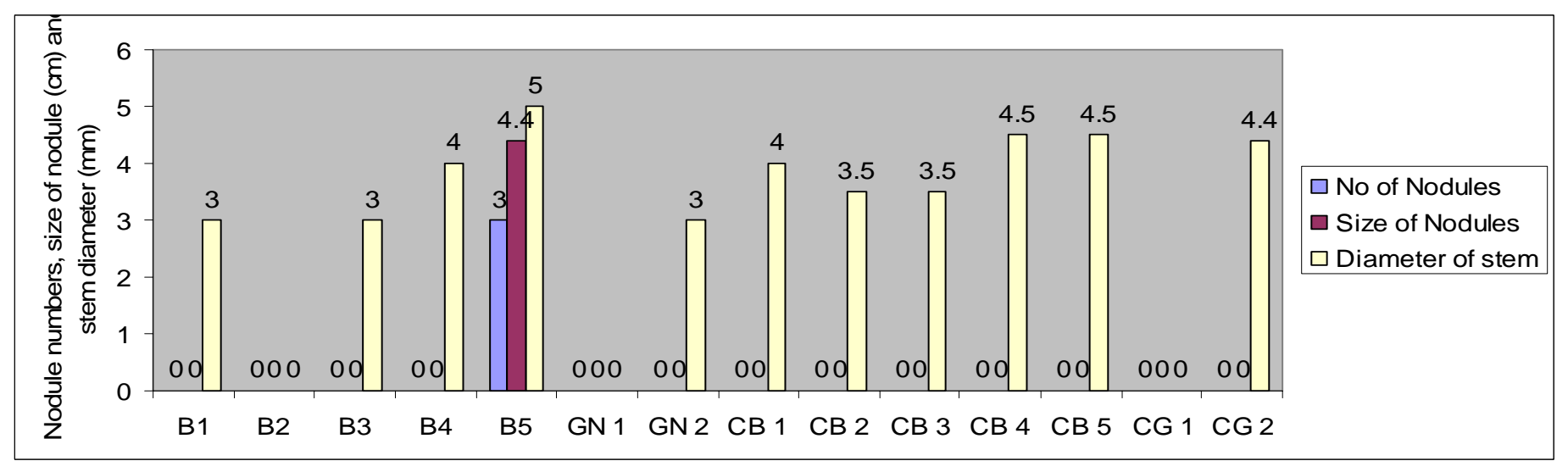

Figure 3: Composite bar chart of number of nodules, nodule size and stem diameter of beans and groundnut varieties grown on sandy soil and control

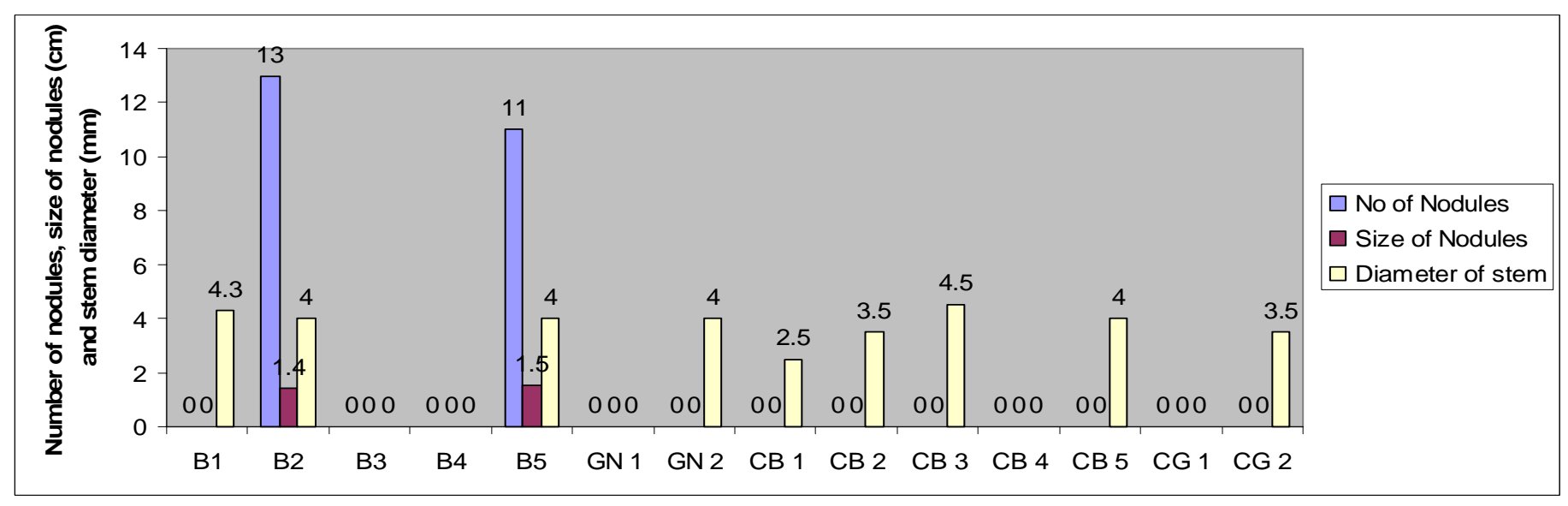

Figure4: Composite bar chart showing numbers of nodules, nodule size and stem diameter of beans and groundnut varieties grown on clay soil and control 


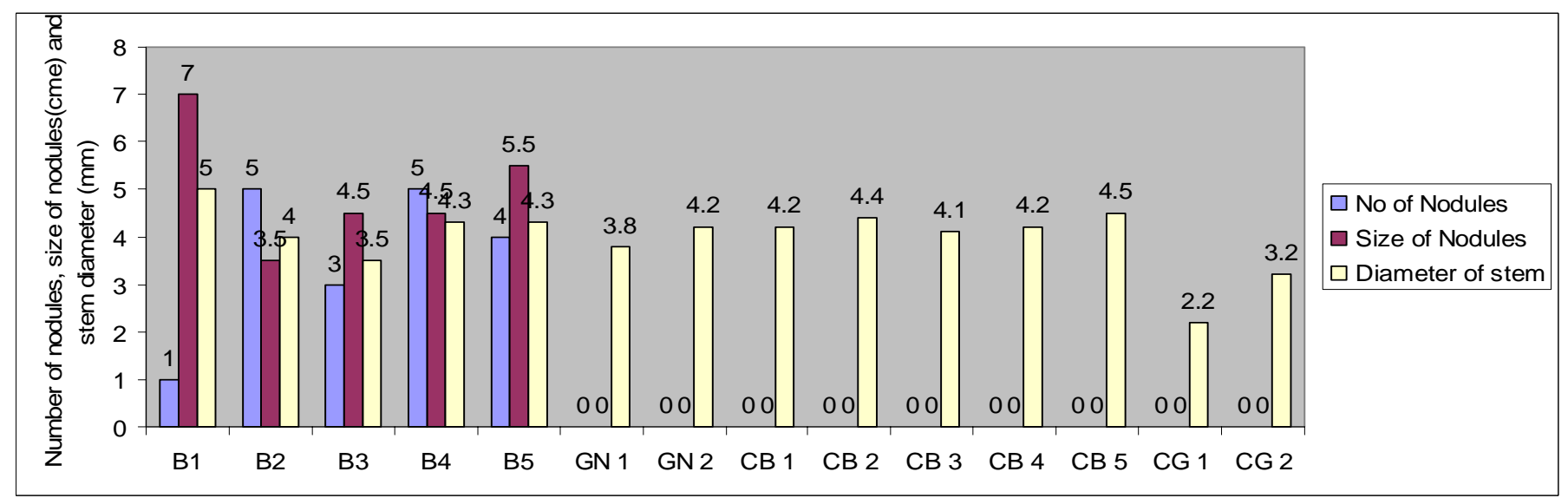

Figure 5: Composite bar chart showing numbers of nodules, nodule size and stem diameter of beans and groundnut varieties grown on a mixture of humus/loamy soils and their control

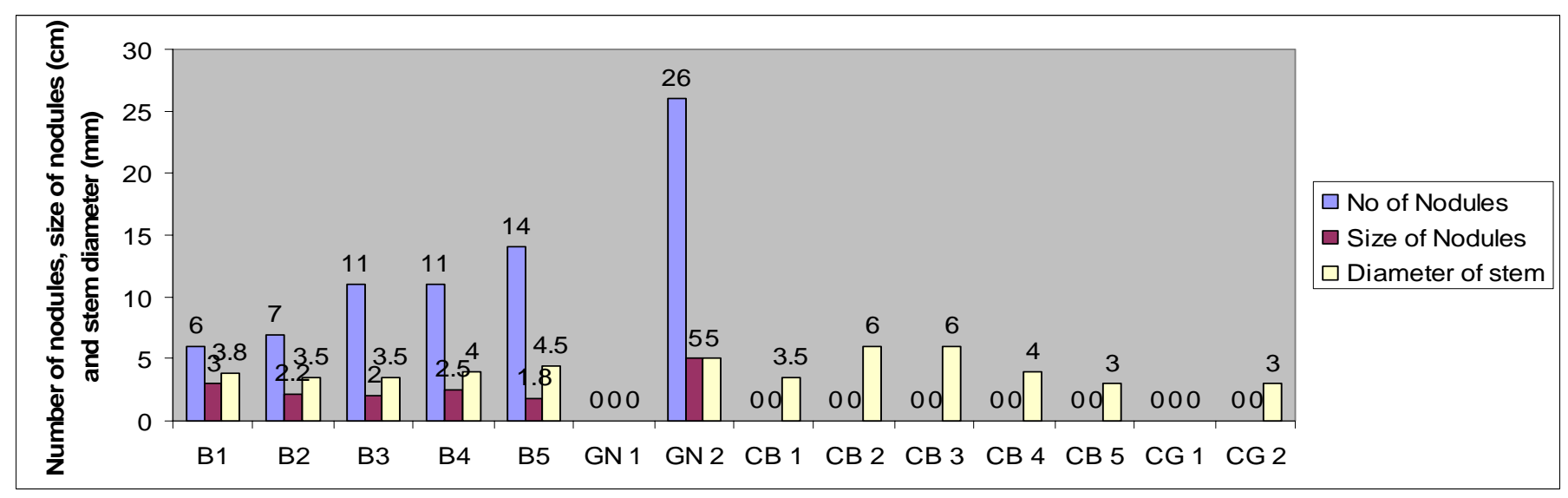

Figure 6: Composite bar chart of number of nodules, nodule size and stem diameter of beans and groundnut varieties grown on sandy/loamy soils and control 

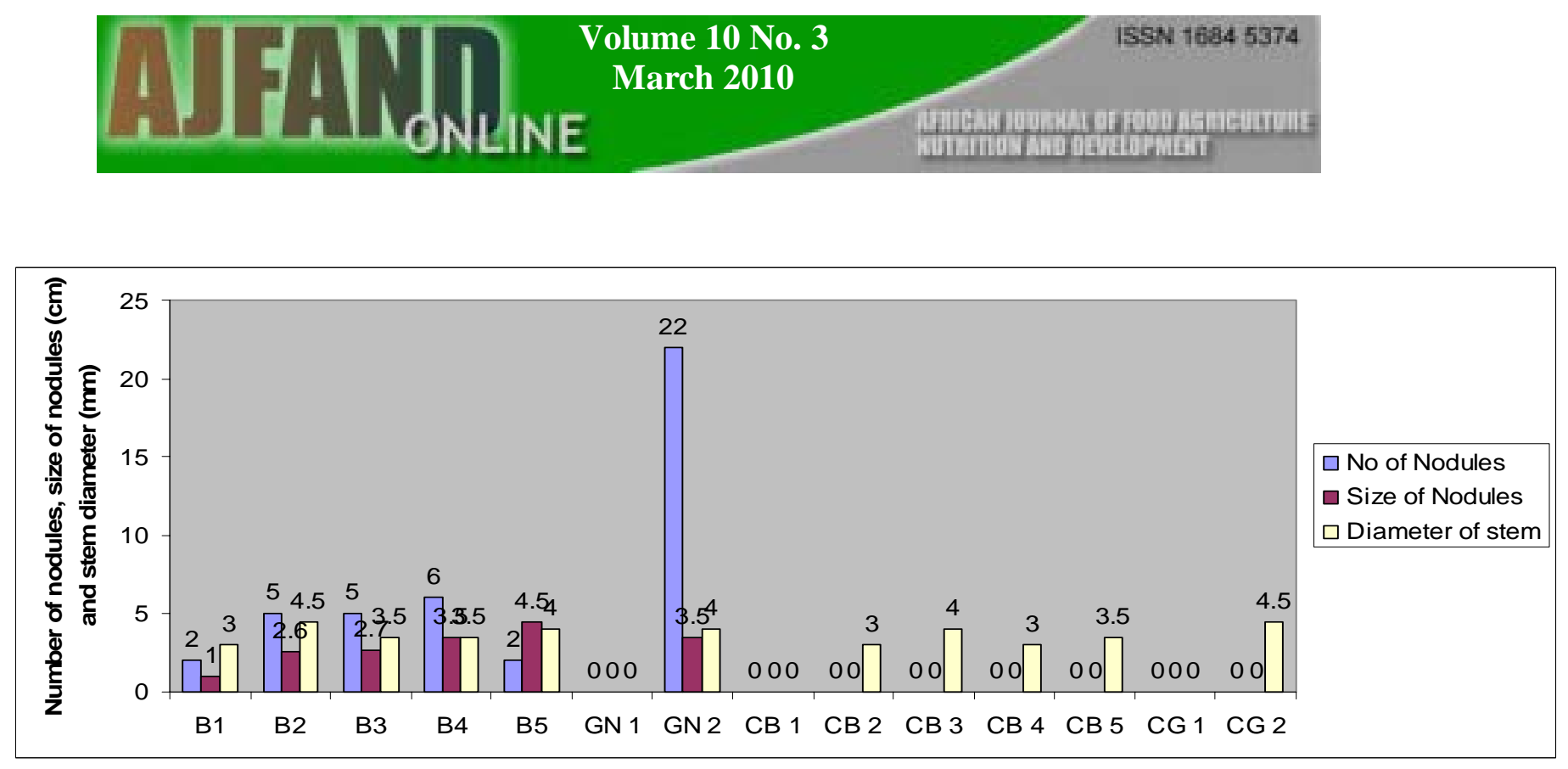

Figure7: Composite bar chart showing numbers of nodules, size of nodules and stem diameter of beans and groundnut varieties grown on mixture of clay/sandy soils and control

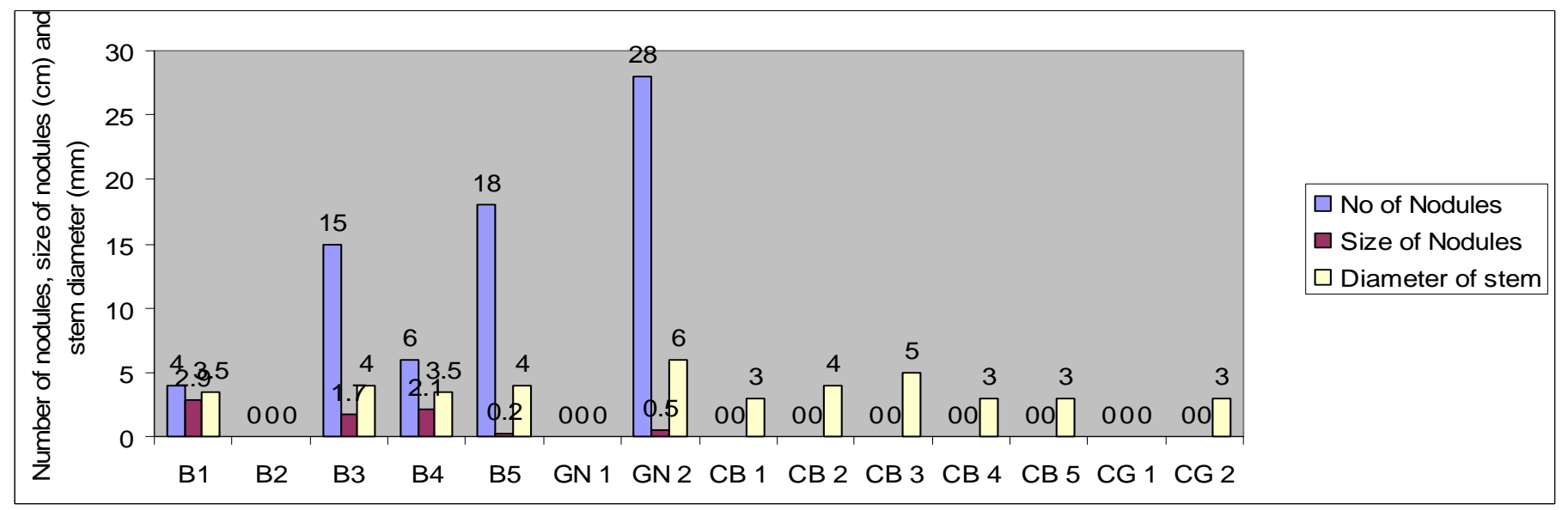

Figure 8: Composite bar chart of number of nodules, nodule size and stem diameter of beans and groundnut varieties grown on a mixture of clay/loamy soils and control 

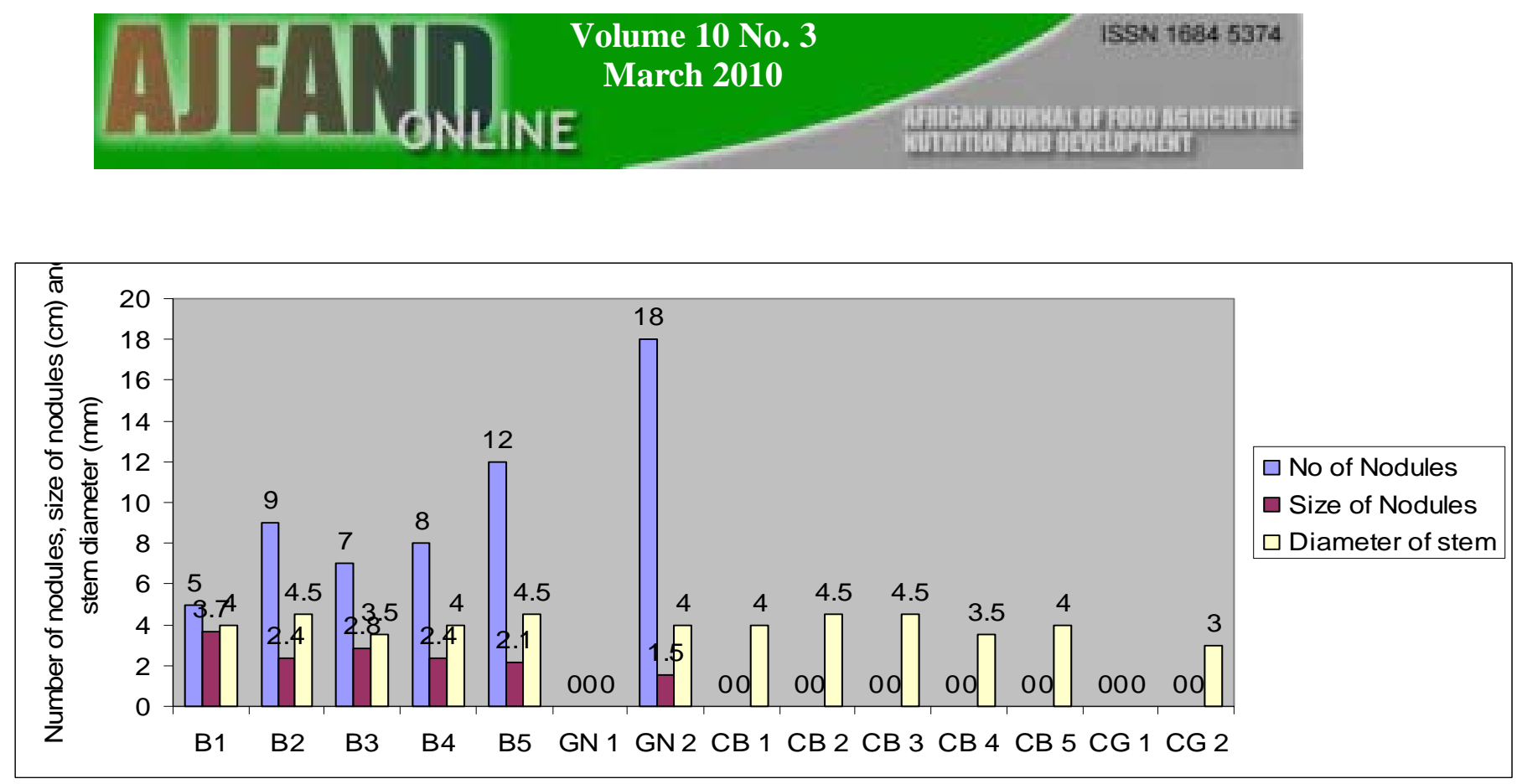

Figure 9: Composite bar chart showing numbers of nodules, nodule size and stem diameter of beans and groundnut varieties grown on clay/humus soils and control

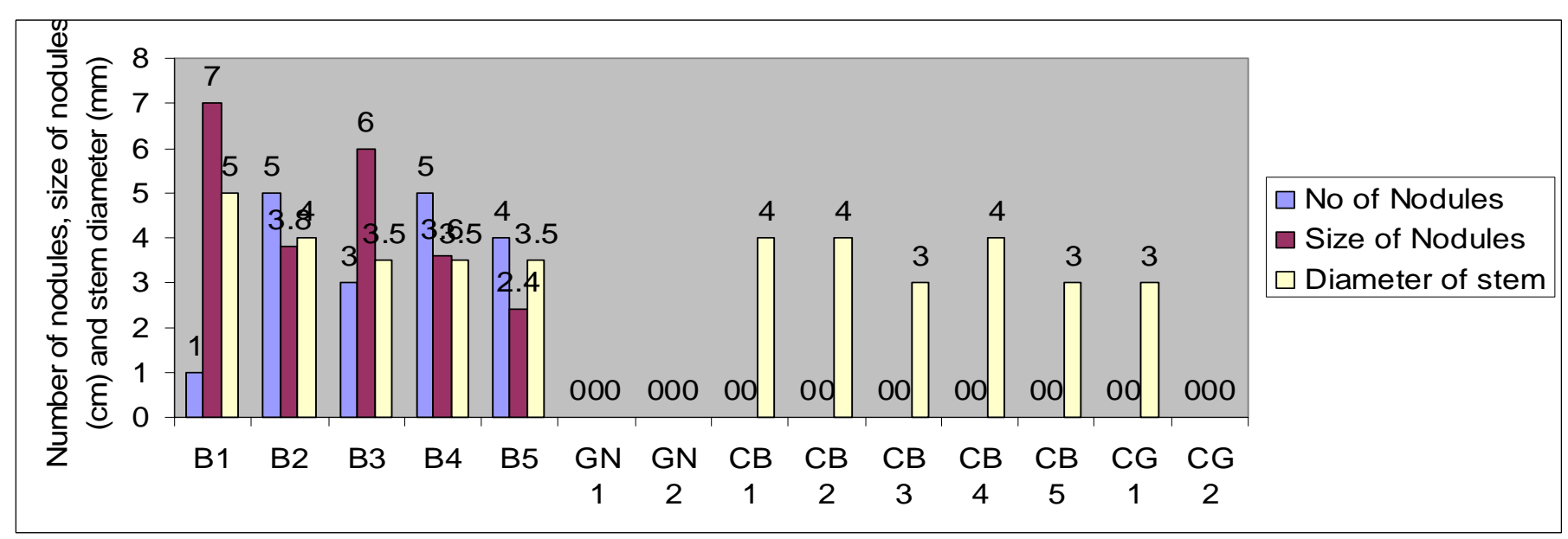

Figure 10: Composite bar chart showing numbers of nodules, nodule size and stem diameter of beans and groundnut varieties grown on sandy/humus soils and control

Key: $\quad \mathrm{N}=$ Number of Nodules formed: $\mathrm{S}=$ Size of nodule formed in millimetre $(\mathrm{mm})$ $\mathrm{D}=$ Diameter of each plant stem in millimetre $(\mathrm{mm}), \mathrm{B}=$ Beans;

$\mathrm{GN}=$ Groundnut $\mathrm{CB}=$ Control beans; $\mathrm{CG}=\mathrm{Control}$ groundnut

\section{DISCUSSION}

Considerable research has been done to determine nodulation on the roots of leguminous plants $[4,8,14,23]$. This report investigated the extent of nodulation of beans and groundnut varieties in different soil types, their mixtures and the abundance of nodules formed by each plant type, size of nodules and the diameter of the resulting stems. During the study, it was observed that the extent of nodules formation differ between soil types and their mixtures. Of all the soil types, loamy and humus soils 
appear to encourage nodulation more than the rest soil types (clay and sandy soils). This is due to the fact that all beans and groundnut varieties except Groundnut 1 nodulated in these two soil types (Fig.1, 2, 3 and 4). Although Beans 2 and 5 nodulated in both clay and sandy soils, only Bean 5 nodulated in sandy soil. Beans 3 and Groundnut 2 nodulated better in loamy soil than the other beans and groundnut varieties, whereas Beans 3 produced more nodules in humus soil than the other varieties. Although all the soil mixtures supported nodulation, the extent of nodule formation differs tremendously. While humus/loamy soil encouraged nodulation of all bean varieties (Fig. 5), the two groundnut varieties did not nodulate in this soil mixture. Several bean and groundnut varieties nodulated in all the soil mixtures; however, Groundnut 1 did not nodulate in all the soil mixtures (Figures 5, 6, 7, 8, 9, 10). The mean values of number of nodules formed on root as well as mean size of nodules and diameter of beans and groundnut varieties were determined and represented graphically. It appears from this study that the fewer the number of nodules formed the larger is the mean nodules size; contrariwise, the more the number of nodules the smaller is the mean nodule size for all the soil samples examined (Figures 1 - 10). From the results obtained (Figures $1-10$ ), it was observed that the mean diameter of the stem is independent of the number of nodules formed and that whether a nodule is formed or not the diameter of the plant remains the same. It may be that growth of the plant variety does not depend on relationship between the plant and the microsymbiont but that the gene that control growth is chromosomally borne in the macrosymbiont, hence the observed growth in the absence of nodulation. Several workers have reported that nodule formation precede plant growth and root hair formation $[11,15]$. The decrease in the number of nodules formed in humus soil and other soils mixed with humus as observed in this study could be explained on the high nutrient level in this soil type. Studies made by some workers revealed that addition of ammonium or nitrate has inhibitory effects on root infection by rhizobial organisms [24] as well as soils rich in these nutrients. This may be responsible for the poor nodulation observed in humus soils and its mixtures. On the other hand, soil $\mathrm{pH}$ has a correlative bearing on the phage and Rhizobia infection of root nodules of plants and that phage lysed only rhizobial strains from certain sero-group [25]. In addition, up to $50 \%$ of the rhizobial strains in a serological group were not sensitive to the phage that was isolated. This insensitivity to phage may have been responsible for the ability of some variety of plants to nodulation while others could not nodulate. Other workers correlated the distribution of sero-group of nodule-forming bacteria with the $\mathrm{pH}$ of the soil $[26,27]$. In their report they observed that a sero-group dominated in nodules of soybeans grown on alkaline soil, while another sero-group dominated in nodules from acidic or neutral soils. The observations by this group of workers may have been responsible for the discrepancy in the differential nodulation observed for the various cultivars of beans and groundnut used in this study. Studies elsewhere found the bacteriophage for $R$. meliloti in every alfalfa field examined but only occasionally in fields not growing alfalfa. They added that phage lytic activity could reduce the population of certain strains of rhizobia in the rhizophere allowing only certain other serogroups to prevail in that environment [28]. Hence, phage specificity for sero-groups of rhizobia could have played an important role in elimination of typical Rhizobium species required for nodule formation in groundnut ALR1 in most

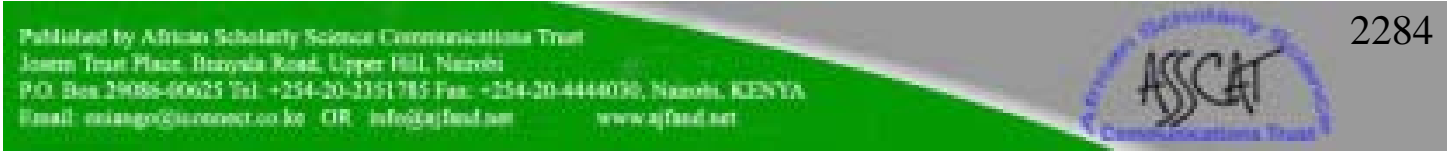


cases of soil/soil mixtures used and in few cases in ALR2. Other studies observed that different types of nodule-forming bacteria are equally effective to some host. $\mathrm{He}$ observed that the size, number and distribution of nodules depend on whether the association is effective or ineffective and that the difference in type of nodulation is sometimes evident among the types of rhizobial strains, even when they are ineffective [29]. This means that nodulation is confronted with a lot of barrier ranging from the $\mathrm{pH}$ of the soil, the presence of phage particles, the type of plant cultivated on the land as well as the type of the nodule-forming bacteria present in the soil. There seems to be interplay between these factors in respect of the results obtained in this study.

The large sizes of nodules in legumes planted in humus soil could be explained on the basis of high nutrient level of humus soils. Observations made elsewhere have it that humus provides the essential nutrient to the soil [30]. From this finding, it is pertinent to state that legume type does not determine the number of nodules that are formed but the soil type and the preponderance of nodule-forming microbes in the soil environment may account for the observed phenomenon. The poor nodulation observed in soil types viz a vis the legumes employed may not explain whether some soils are fairly, highly or poorly productive, but may have stemmed from the fact that the type of rhizobial organisms present in such soils are non-specific for the type of legume employed $[13,31]$.

Groundnut ALR1 failed to nodulate in all the soil samples and their mixtures except on loamy soil. This may be a mutant variety referred to as rhd2 (root hair defective) mutant spoken of by [15] in their study of failed nodulation in some mutant variety of Arabidopsis. Previous studies have shown that Arabidopsis develops unusually short root hairs as they lack the enzymes capable of catalyzing the formation of reactive oxygen species (ROS), which is needed for the normal elongation of root hairs in Arabidopsis [5, 15]. The rhd 2 mutants were noted to be deficient in establishing a root hair tip-focused $\mathrm{Ca}^{2+}$ gradient, because of an altered activity of a $\mathrm{Ca}^{2+}$ influx channel. They observed further that when such plants were exposed to exogenous hydroxyl radicals there was a partial restoration of the ability of rhd 2 root hairs to establish a $\mathrm{Ca}^{2+}$ gradient. This deficiency may have been responsible for the observed phenomenon. In addition, studies elsewhere reported that control plants and transgenic plants that expressed mutant pea lectin did not form nodules or infection threads when inoculated with low numbers of the same strain [32]. This may have been responsible for inability of Groundnut ALR1 and other beans varieties to nodulate in some soils and soil mixtures. Further studies noted that since infection threads often outnumber nodules, it is either that infection thread progression is actively stopped by the plant or infection thread extension and movement out of root epidermal cells are inherently inefficient [5, 33]. All these factors may have contributed to the failed nodulation observed in Groundnut ALR1. It may be possible that infection thread progression may have been stopped before nodule formation in varieties that failed to nodulate in some soils and their mixtures. 
The observations were later subjected to statistical analysis using SPSS version 17. Statistical analysis of the results obtained show that at 5\% confidence level, number of nodules and diameter of each plant stem are not significant while size of nodule formed is significant. Further analysis showed there is significant positive association for nodule size and nodules number for clay soil at 5\% confidence level $(\mathrm{P}<005)$. However, there is significant negative association for nodules size and numbers for clay and humus mixtures at 5\% confidence level $(\mathrm{P}<0.005)$. Using independent t-test for difference in means between nodules number and size, it was found that only sand/clay mixture and clay/humus are significant at 5\% ( $\mathrm{P}<.005)$ confidence level, while other soil types and their mixtures were not significant at the same level of confidence. This means there is no significant difference between the means of the number of nodules and nodule size. Comparison among the soil types using Tamhane's T2 post hoc test, thus revealed that clay and sandy soils were poor in encouraging nodule formation as they have the highest mean differences, while sandy/humus and humus were more efficient at enhancing nodule formation, followed by clay/humus and clay/sandy.

Inference is there made that loamy soil appears to be the best soil for the cultivation of leguminous plants. In was observed in terms of number of nodules, size of nodules and diameter of plant stem, that averagely, beans and groundnut varieties grown on loamy soil and its mixture did better than other soil types and their mixtures. Therefore, loamy soil appears to be more efficient at producing large numbers of nodules. If nodule formation is a prerequisite to plant productivity and yield, then it will be appropriate to recommend loamy soil for the cultivation of leguminous plants especially beans and groundnut. This recommendation is in line with findings that breeding of nodulated red clover (Rifolium pretense) resulted in high yield of the plant [33]. Nodule formation is well supported in loamy soil due to its low $\mathrm{pH}$ and availability of phosphorus and molybdenum. This is in line with the previous conclusions of [32]. Although loamy soil and its mixtures did support nodulation with varied efficiency, a fundamental question here is how the mixture of clay and sandy soils supports nodulation, when each of the soil types did not support nodule formation.

\section{CONCLUSION}

The study revealed that groundnut ALR1 failed to nodulate in all soil samples employed and their mixtures except on loamy soil. It was also observed that nodulation and size of nodules differ between soil types, soil types and their mixtures. In addition, loamy and humus soils encouraged nodulation more than the other soil types since all beans varieties and groundnut ALR2 nodulated well in these soils. On the other hand, sandy/humus and humus/loamy were more supportive of nodule formation, followed by clay/humus and clay/sandy. The study also noted that fewer the number of nodules, the larger the mean size of the nodules. The converse was also true. The mean diameter of the stem is independent of the number and size of nodules formed. Inference is therefore made that the best soil types and their combination essential for healthy growth of these cultivars are loamy, humus,

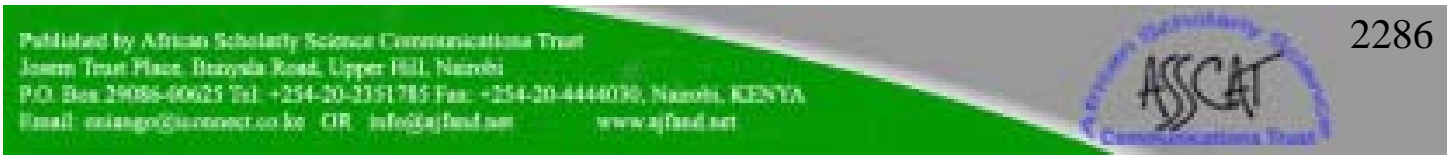




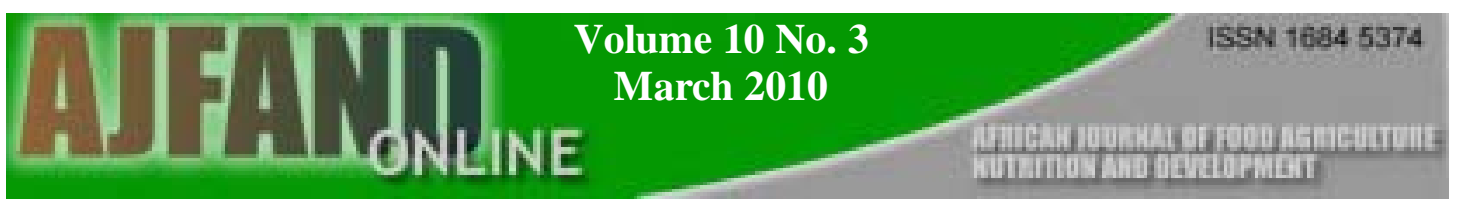

sandy/humus, and humus/loamy. The poor nodulation observed in some soil types vis a vis the legumes employed may not explain their productivity, but may have stemmed from the fact that the type (s) of rhizobial organisms present in such soils are non-specific and hence could not infect the cultivar (s) of legumes employed in this study.

\section{ACKNOWLEDGEMENT}

Many thanks to Stored Product Research Institute especially Mr. Livinus Okeke for the provision of the cultivars of beans and groundnut used in this study. The authors are also grateful to the soil scientist (Mr. Samson Badejo) of the Lagos State Ministry of Agriculture and Natural Resources (Soil Science Department) for providing the soils used in the study. Many thanks to members of the Department of Biological Science, Yaba College of Technology, Yaba Lagos, Nigeria for their individual contributions to the success of this study. 


\section{REFERENCES}

1. Cleveland CC, Townsend AR, Schimel DS, Fisher N, Howarth RW, Hedin LO, Perakis SS, Latty EF, von Fischer JC, Elseroad A and MF Wasson Global patterns of terrestrial Biological nitrogen $\left(\mathrm{N}_{2}\right)$ fixation in Natural ecosystems. Global Biogeochem. Cycles 1999; 13(2): 623 - 645.

2. Altieri K, Duce RA and $\mathbf{J}$ Laroche Impacts of Atmospheric Anthropogenic Nitrogenic nigtrogen on the open ocean. Science, 2008; 320 (5878): 893-897.

3. Bethoux JP and G Copin-Montegut Biological fixation of atmospheric nitrogen in the Mediterranean. Limnology and Oceanography, 1986; 31 (6): 1353-1358.

4. Schlegel HG General Microbiology, $7^{\text {th }}$ edition, Cambridge CB22RU, United Kingdom, 1992: 655.

5. Gage DJ Infection and invasion of roots by symbiotic, nitrogen-fixing rhizobia during nodulation of temperate legumes. Microbiol. Mol. Biol. Rev. 2004; 68: 280-300.

6. Freiberg C, Fellay R, Bairoch A, Broughton WJ, Rosenthal A and X Perret Molecular basis of symbiosis between Rhizobium and legumes. Nature 1997; 387: 394-401.

7. Kaneko T, Nakamura Y, Sato S, Minamisawa K, Uchiumi T, Sasamoto S, Watanabe A, Idesawa K, Iriguchi M, Matsumoto M, Shimpo S, Tsuruoka H, Wada T, Yamada $M$ and $S$ Tabata Complete genomic sequence of nitrogen-fixing symbiotic bacterium Bradyrhizobium japonicum USDA110. DNA Res. 2002; 9: 189-197.

8. Daramola AM, Igbokwe EM, Mosuro GA and JA Abdullahi Agricultural Science, $2^{\text {nd }}$ edition, University Press Plc, Ibadan, 2000: 191.

9. Geurts R, Fedorova $\mathbf{E}$ and $\mathbf{T}$ Bisseling Nod factor signaling genes and their function in the early stages of Rhizobium infection. Curr. Opin. Plant Biol. 2005; 8: 346-352.

10. Blauenfeldt J, Joshi PA, Gresshoff PM and GA Caetano-Anolles Nodulation of white clover (Trifolium repens) in the absence of Rhizobium. Protoplasma 1994; 179 (3-4): 106-110.

11. Tirichine L, James EK, Sandal N and J Stougaard Spontaneous Root-nodule formation in the Model Legume Lotus japonicus: A Novel Class of Mutants Nodulates in the Absence of Rhizobia. MPMI 2006; 19(4): 373 - 381. 
12. Niwa S, Kawaguchi M, Imazumi-Anraku H, Chechetka SA, Ishizaka M, Ikuta A and H Kouchi Responses of a model legume Lotus japonicus to lipochitin oligosaccharide nodulation factors purified from Mesorhizobium loti JRL501. Mol Plant-Microbe Interact. 2001; 14: 848-856.

13. Benson DR and WB Silvester Biology of Frankia strains, actinomycete symbionts of actinorhizal plants. Microbiol. Rev. 1993; 57:293-319.

14. Nester EW, Denis GA, Evans RC, Nancy NP and TN Martha Microbiology (A Human Perspective), $3^{\text {rd }}$ edition, McGraw-Hill Companies Inc., New York, 2001: 820 .

15. Foreman J, Demidchik V, Bothwell JH, Mylona P, Miedema H, Torres MA, Linstead P, Costa S, Brown C, Jones JD, Davies JM and L Dolan Reactive oxygen species produced by NADPH oxidase regulate plant cell growth. Nature 2003; 422: 442-446.

16. Priefer UB, Aurag J, Boesten B, Bouhmouch I, Defez R, Filali-Maltouf A, Miklis M, Moawad H, Mouhsine B, Prell J, Schluter A and B Senatore Characterisation of Phaseolus symbionts isolated from Mediterranean soils and analysis of genetic factors related to pH tolerance. J. Biotechnol. 2001; 91(2-3): $223-236$.

17. Mhamdi R, Laguerre G, Aouani M E, Mars M and N Amarger Different species and symbiotic genotypes of field rhizobia can nodulate Phaseolus vulgaris in Tunisian soils. FEMS Microbiol. Ecol. 2002; 41(1): 77-84.

18. Aouani ME, Mhamdi R, Mars M, Elayeb $\mathbf{M}$ and $\mathbf{R}$ Ghrir Potential for inoculation of common bean by effective rhizobia in Tunisian soils. Agronomie 1997; 17(9-10): 445-454.

19. Nour SM, Cleyet-Marel JC, Normand $\mathbf{P}$ and MP Fernandez Genomic heterogeneity of strains nodulating chickpeas (Cicer arietinum L.) and description of Rhizobium mediterraneum sp. nov. Int. J. Syst. Bacteriol. 1995; 45(4): 640-648.

20. Nour SM, Fernandez MP, Normand $\mathbf{P}$ and JC Cleyet-Marel Rhizobium ciceri sp. nov., consisting of strains that nodulate chickpeas (Cicer arietinum L.). Int. J. Syst. Bacteriol. 1994; 44(3): 511-522.

21. Cardoso JD, Gomes DF, Goes KC, Fonseca GPO, Dorigo NDAS.Jr , Hungria $M$ and DS Andrade Relationship between total nodulation and nodulation at the root crown of peanut, soybean and common bean plants. Soil Biology and Biochemistry 2009; 41: 1760-1763. 
23. Andrade DS, Murphy PJ and KE Giller The Diversity of Phaseola Nodulating Rhizobial population is altered by liming of acid soils. J. of Appl. Environ. Microbiol., 2002; 68(8): 4025 - 4034.

24. Streeter $\mathbf{J}$ Inhibition of legume nodule formation and nitrogen fixation by nitrate. CRC. Crit. Rev. Plant Sci. 1988; 7: 1-23.

25. Kowalski M, Ham GE, Frederick LR and LI Anderson Relationship between strains of Rhizobium japonicum and their bacteriophages from soil and nodules of field-grown soybeans. Soil Science (1974); 118 (3): 221-228.

26. Ham GE, Frederick LR and IC Anderson Serogroups of Rhizobium japonicum on soybeans nodules sampled in Iowa. Agron J. (1971); 63: 69-72.

27. Damirgi SM, Federick LR and IC Anderson Serogroups of Rhizobium japonicum in soybeans nodules as affected by soil types. Agron J. 1967; 59: 1012.

28. Katneslon $\mathbf{H}$ and JK Wilson. Occurrence of Rhizobium meliloti bacteriophage in soils. Soil Science 1941; 5(1): 59-64.

29. Shuichi I Studies on root-nodule bacteria of leguminous plants: II. Relationship between nodule bacteria and leguminous plants. Japanese Society of soil science and plant nutrition 1955; 26(5): 172 - 174.

30. Pelczar MJ, Chan ECS and NR Krieg Microbiology, $5^{\text {th }}$ edition, McGrawHill, Inc., New York, 1993: 918.

31. Benson D R and ML Clawson Evolution of the actinorhizal plant nitrogenfixing symbiosis,. In E. Triplett (ed.), Prokaryotic nitrogen fixation: a model system for the analysis of a biological process. Horizon Scientific Press, Wymondham, England, 2000. p. 207-224.

32. van Rhijn P, Fujishige NA, Lim PO and AM Hirsch Sugar-binding activity of pea lectin enhances heterologous infection of transgenic alfalfa plants by Rhizobium leguminosarum biovar viciae. Plant Physiol. 2001; 126: 133-144.

33. Nutman PS and J Riley Breeding of nodulated red clover (Trifolium pretense) for high yield. Annal of Appl. Bio., 1962; 98(2): 319-331. 